\title{
Disparities in the frequency of fruit and vegetable consumption by socio-demographic and lifestyle characteristics in Canada
}

\author{
Sunday Azagba and Mesbah F Sharaf
}

\begin{abstract}
Background: The health benefits of adequate fruit and vegetable ( $F \& V$ consumption are significant and widely documented. However, many individuals self-report low F\&V consumption frequency per day. This paper examines the disparities in the frequency of F\&V consumption by socio-demographic and lifestyle characteristics.

Method: This study uses a representative sample of 93,719 individuals from the Canadian Community Health Survey (2007). A quantile regression model is estimated in order to capture the differential effects of F\&V determinants across the conditional distribution of F\&V consumption.

Results: The conditional and unconditional analyses reveal the existence of a socioeconomic gradient in F\&V consumption frequency, in which the low income-education groups consume F\&V less frequently than the high income-education groups. We also find significant disparities in F\&V consumption frequency by demographic and lifestyle characteristics. The frequency of F\&V consumption is relatively lower among: males, those in middle age, singles, smokers, individuals with weak social interaction and households with no children. The quantile regression results show that the association between F\&V consumption frequency, and socio-demographic and lifestyle factors varies significantly along the conditional F\&V consumption distribution. In particular, individual educational attainment is positively and significantly associated with F\&V consumption frequency across different parts of the F\&V distribution, while the income level matters only over the lower half of the distribution. F\&V consumption follows a U-shaped pattern across the age categories. Those aged 30-39, 40-49 and 50-59 years consume F\&V less frequently than those aged 18-29 years. The smallest F\&V consumption is among the middle aged adults (40-49).

Conclusions: Understanding the socio-demographic and lifestyle characteristics of individuals with low F\&V consumption frequency could increase the effectiveness of policies aimed at promoting F\&V consumption. The differential effects of individual characteristics along the F\&V consumption distribution suggest the need for a multifaceted approach to address the variation in F\&V consumption frequency.
\end{abstract}

Keywords: fruit, vegetable, socio-demographic characteristics, lifestyle, quantile regression

\section{Introduction}

The health benefits of fruit and vegetable (F\&V) consumption are significant and widely documented [1,2]. According to reports from the World Health Organization and the Food and Agriculture Organization [3], daily consumption of five servings, or a minimum of 400 grams, of F\&V helps in preventing several diseases. Several empirical studies document that a diet rich in F\&V is negatively

\footnotetext{
* Correspondence: m_shara@live.concordia.ca

Department of Economics, Concordia University, 1455 de Maisonneuve Blvd. West, Montréal, Quebec, H3G 1M8, Canada
}

associated with the risks of: diabetes [4], obesity [5,6], strokes [7], high blood pressure [8]. Sufficient F\&V consumption also helps in managing body weight because most F\&V are high in water and fiber, and low in fat [5]. Globally, inadequate F\&V consumption is responsible for annual deaths of 2.7 million, $11 \%$ of strokes, $31 \%$ of ischemic heart diseases and 19\% of gastrointestinal cancers $[3,9]$.

In spite of the numerous benefits of consuming $F \& V$, many individuals self-report low F\&V consumption frequency per day. For example, in 2010, 56.7\% of Canadians

\section{() Biomed Central}


aged 12 years and older reported consuming F\&V less than five times a day [10], while in the U.S $67.5 \%$ of adults consume fruit less than two times per day and $73.7 \%$ consume vegetables less than three times per day [11].

Dietary choices including F\&V consumption are largely affected by demographic factors like age and gender $[12,13]$, psychological factors [14], socioeconomic class [15] and lifestyle behavior. Studies have shown that people of higher socioeconomic classes have healthier and nutritionally more balanced diets than those of lower socioeconomic classes [16-19]. Several studies find that, in terms of F\&V consumption: men consume less than women $[18,20-22]$, smokers consume less than non-smokers $[21,22]$, and singles consume less than married people $[16,18]$. For example, Baker and Wardle [20] find that females consume more F\&V than males, which they attribute to the poorer nutritional knowledge of males. The authors also find that males are less likely to know the recommended $F \& V$ intake, and the benefits associated with F\&V consumption. Thompson et al. [22] find that individuals with low consumption of F\&V are more likely to smoke, to be young and male.

Previous related studies mostly use standard multiple linear or binary choice regressions to estimate the determinants of the conditional mean of F\&V consumption or the probability of consuming more than five servings of F\&V a day. Results from these methods may be misleading insofar as individual F\&V consumption responds differently to changes in the covariates at different regions of the F\&V consumption distribution [23]. Multiple linear regressions treat different parts of the conditional distribution of F\&V consumption equally and consider the marginal effect of the explanatory variables to be the same along the F\&V consumption distribution.

This paper examines the socio-demographic and lifestyle determinants of $F \& V$ consumption frequency using quantile regression. Quantile regression allows the effect of each explanatory variable to vary along different percentiles of the conditional distribution of F\&V consumption. Examining how individual socio-demographic and lifestyle factors influence the F\&V consumption frequency at different consumption levels is particularly important in the nutrition literature where attention is given to the tails of the distribution.

\section{Methods \\ Data}

This study is based on a sample from the 2007 Canadian Community Health Survey (CCHS), a nationally representative, cross-sectional survey of 131,000 individuals of the Canadian population. It collects vital information on health-related behavior, as well as corresponding economic and socio-demographic variables. The survey excludes those living on Indian Reserves and Crown
Lands, institutional residents, full-time members of the Canadian forces, and residents of certain remote regions, representing about $98 \%$ of the Canadian population aged 12 years and over. The sample of interest comprises of those aged 18-69 years which includes 93,719 individuals.

The frequency of F\&V consumption, which is the dependent variable in this study, is the total number of times per day that a respondent consumes F\&V. Statistics Canada derived total frequency of F\&V consumption from a food frequency questionnaire. For a list of detailed survey questions and methods used, see Statistics Canada [24].

The study uses control variables that have been shown in previous studies to be important determinants of F\&V consumption [e.g. [15-19]. Age is stratified into five categories: 18-29 (reference group), 30-39, 40-49, 50-59 and 60-69. Gender is represented by a dummy variable (male $=0$, female $=1$ ). Marital status is represented by three dummy variables: married, separated and single (reference group). Four dummy variables are used to represent an individual's educational attainment: less than secondary (reference group), secondary, some post secondary, and post secondary. Household income is represented by four dummy variables: low income (reference group), low middle income, high middle income and high income. A dummy variable indicating individual social interaction (sense of belonging to a local community) is included (strong $=1$, weak $=0$ ). Smoking status is classified as: never smoker (reference group), current smoker, and former smoker. Immigration status is captured by a dummy variable (immigrant $=1$, non-immigrant $=0$ ). A dummy variable is used to indicate if a household has children, with having none as the reference group. In order to capture cultural or regional differences in F\&V consumption, province fixed-effects are represented in five categories: Quebec (reference group), Ontario, British Colombia, Atlantic (comprising New Brunswick, Prince Edward Island, Nova Scotia and Newfoundland and Labrador) and Western (Alberta, Saskatchewan and Manitoba). A detailed definition of variables used in the study is presented in Table 1. The data used are the public-use-microdata version released by Statistics Canada, hence ethical approval is not required.

\section{Statistical Analysis}

To examine the disparities in $F \& V$ consumption frequency by socio-demographic and lifestyle factors at different points of the conditional F\&V consumption distribution, the following quantile regression model is estimated:

$$
q_{\mu}\left(F V_{i j} \mid S E S_{i j}, X_{i j}, \varphi_{j}\right)=\beta_{0}^{\mu}+S E S_{i j} \beta_{1}^{\mu}+X_{i j} \beta_{2}^{\mu}+\varphi_{j} \beta_{3}^{\mu}
$$

Where $q_{\mu}$ represents the $\mu$ th quantile of the conditional F\&V consumption distribution. For example, $\mu=$ 
Table 1 Variables description and summary statistics

\begin{tabular}{|c|c|c|c|}
\hline & Variables description & Mean & S.D \\
\hline Fruits \& vegetables & daily consumption of fruits and vegetables (frequency) & 4.95 & 2.72 \\
\hline Age 18-29 & age between 18 to 29 & 0.23 & 0.42 \\
\hline Age $30-39$ & age between 30 to 39 & 0.20 & 0.40 \\
\hline Age $40-49$ & age between 40 to 49 & 0.23 & 0.42 \\
\hline Age $50-59$ & age between 50 to 59 & 0.20 & 0.40 \\
\hline Age $60-69$ & age between 60 to 69 & 0.13 & 0.34 \\
\hline Male & gender is male & 0.50 & 0.50 \\
\hline Female & Gender is female & 0.50 & 0.50 \\
\hline Married & married/living with a partner/common-law & 0.64 & 0.48 \\
\hline Separated & widowed/separated/divorced & 0.10 & 0.30 \\
\hline Single & never married & 0.25 & 0.43 \\
\hline $\begin{array}{l}\text { Less secondary } \\
\text { education }\end{array}$ & completed education is less than secondary & 0.12 & 0.32 \\
\hline Secondary education & completed education is secondary & 0.16 & 0.37 \\
\hline Some post secondary & completed education is some post secondary & 0.09 & 0.28 \\
\hline Post secondary & completed education is post secondary & 0.59 & 0.49 \\
\hline Low income & household income ( less than $\$ 30,000$ ) & 0.20 & 0.40 \\
\hline Low middle income & household income $(\$ 30,000-\$ 49,999)$ & 0.15 & 0.36 \\
\hline High middle income & household income $(\$ 50,000-\$ 79,999)$ & 0.14 & 0.35 \\
\hline High income & household income ( $\$ 80,000$ or more) & 0.35 & 0.48 \\
\hline Strong social interaction & sense of belonging to community (strong) & 0.60 & 0.49 \\
\hline Weak social interaction & sense of belonging to community (weak) & 0.36 & 0.48 \\
\hline Have kids & household with kids & 0.47 & 0.50 \\
\hline No kids & no kids in household & 0.44 & 0.50 \\
\hline Current smoker & daily/occasional smoker & 0.24 & 0.43 \\
\hline Former smoker & former daily/occasional smoker & 0.38 & 0.48 \\
\hline Never smoker & never smoked & 0.36 & 0.48 \\
\hline Immigrants & country of birth is not Canada & 0.22 & 0.41 \\
\hline Non immigrants & country of birth is Canada & 0.75 & 0.43 \\
\hline Quebec & province of residence is Quebec & 0.23 & 0.42 \\
\hline Ontario & province of residence is Ontario & 0.39 & 0.48 \\
\hline British Columbia & province of residence is British Columbia & 0.13 & 0.34 \\
\hline Atlantic provinces & $\begin{array}{l}\text { province of residence is New Brunswick, Prince Edward Island, Nova Scotia and Newfoundland and } \\
\text { Labrador }\end{array}$ & 0.07 & 0.25 \\
\hline Western provinces & province of residence is Alberta, Saskatchewan and Manitoba & 0.16 & 0.37 \\
\hline N & & \multicolumn{2}{|c|}{93,719} \\
\hline
\end{tabular}

The statistics are weighted using the CCHS sampling weights.

50 is the conditional median estimate of F\&V consumption. The subscript $i$ stands for an individual and $j$ for the corresponding province of residence. $\mathrm{F} \& V$ denotes the daily frequency of fruit and vegetable consumption. SES denotes individual socioeconomic characteristics (education and income level). $\boldsymbol{X}$ is a vector of other control variables which includes: age, sex, marital status, immigration status, smoking status and social interaction. $\phi$ represents province fixed-effects, which capture regional and other cultural factors that may be associated with individual F\&V consumption. For example, Quebec, a predominantly French speaking province, is a major F\&V producer in Canada.

\section{Results}

The summary statistics reported in Table 1 show that $59 \%$ of the sample has completed one or more years of post-secondary education and $12 \%$ have a less-than-secondary education. About $35 \%$ of the individuals live in a household with an annual income of more than $\$ 80,000$, while $20 \%$ have household income of less than $\$ 30,000$. $24 \%$ of the sample currently smokes, while $38 \%$ are former smokers. Half of the sample is male and $64 \%$ is married; $47 \%$ have children and $22 \%$ are immigrants.

Table 1 shows that the average F\&V consumption frequency is 4.95 per day. Although the population average implies high F\&V consumption frequency, Figure 1 


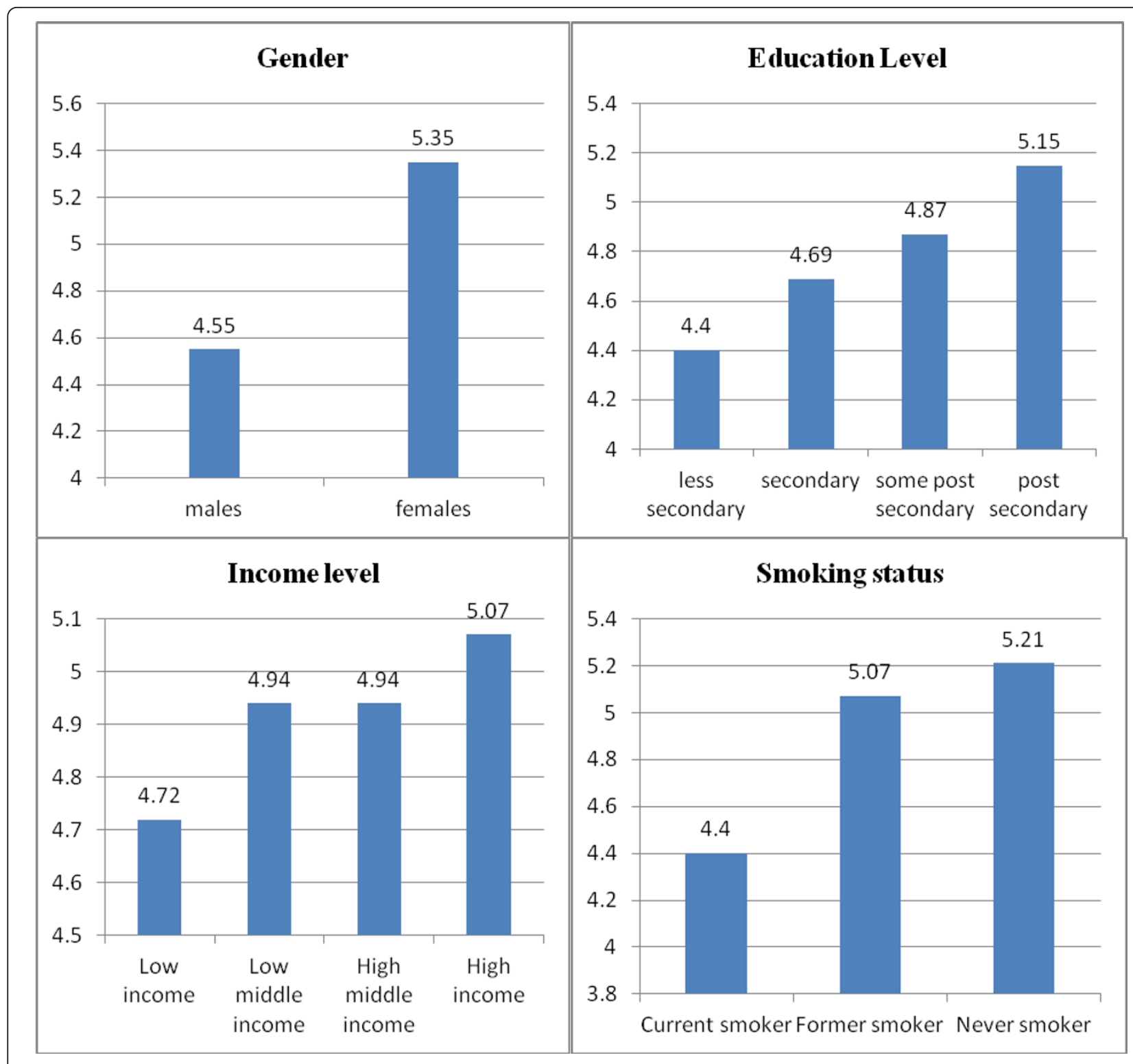

Source: Authors' compilation using data from CCHS (2007).

Figure 1 Average daily consumption frequency of fruits and vegetables by selected characteristics.

reveals wide disparities by socio-demographic and lifestyle characteristics. The standard deviation of 2.7 reported in Table 1 indicates a large variation in $F \& V$ consumption among individuals in the sample.

Figure 1 depicts the average daily F\&V consumption frequency by selected characteristics. According to this unconditional analysis, the daily F\&V consumption frequency is less for males and current smokers compared to females and never smokers respectively. The results also confirm the standard socioeconomic (SES) gradient in F\&V consumption, where people with higher SES consume F\&V more frequently than those with lower SES.

Table 2 presents quantile regression estimates for some selected quantiles of the F\&V distribution, as well as estimates for a baseline, ordinary least squares (OLS) model. The OLS and quantile regression results shown in Table 2 include the covariates described in the data section. Figure 2 summarizes the differences between the OLS and quantile estimates for socio-economic variables.

The multivariate analyses which control for potential confounders are consistent with the descriptive statistics 
Table 2 Fruit and vegetable regression results: OLS and quantile estimates

\begin{tabular}{|c|c|c|c|c|c|c|c|}
\hline & \multirow[t]{2}{*}{ OLS } & \multicolumn{6}{|c|}{ Quantile regression estimates } \\
\hline & & (5) & (15) & $(25)$ & $(50)$ & (75) & $(90)$ \\
\hline \multicolumn{8}{|c|}{ Less secondary (reference. group) } \\
\hline \multirow[t]{2}{*}{ post secondary } & $0.575^{* * *}$ & $0.369^{* * *}$ & $0.467^{* * *}$ & $0.490^{* * *}$ & $0.560^{* * *}$ & $0.678^{* * *}$ & $0.733^{* * *}$ \\
\hline & $(0.044)$ & $(0.041)$ & $(0.042)$ & $(0.042)$ & $(0.041)$ & $(0.057)$ & $(0.107)$ \\
\hline \multirow[t]{2}{*}{ some post secondary } & $0.318^{* * *}$ & $0.243^{* * *}$ & $0.290^{* * *}$ & $0.232^{* * *}$ & $0.305^{* * *}$ & $0.426^{* * *}$ & $0.307^{* *}$ \\
\hline & $(0.066)$ & $(0.067)$ & $(0.056)$ & $(0.059)$ & $(0.060)$ & $(0.085)$ & $(0.154)$ \\
\hline \multirow[t]{2}{*}{ secondary } & $0.203^{* * *}$ & $0.185^{* * *}$ & $0.209^{* * *}$ & $0.173^{* * *}$ & $0.161^{* * *}$ & $0.139^{* *}$ & $0.368^{* * *}$ \\
\hline & $(0.057)$ & $(0.048)$ & $(0.047)$ & $(0.049)$ & $(0.049)$ & $(0.070)$ & $(0.138)$ \\
\hline \multicolumn{8}{|c|}{ Low income (reference group) } \\
\hline \multirow[t]{2}{*}{ High income } & $0.129^{* * *}$ & $0.282^{* * *}$ & $0.242^{* * *}$ & $0.238^{* * *}$ & $0.190^{* * *}$ & 0.052 & 0.0212 \\
\hline & $(0.041)$ & $(0.037)$ & $(0.034)$ & $(0.037)$ & $(0.037)$ & $(0.053)$ & $(0.010)$ \\
\hline \multirow[t]{2}{*}{ High middle income } & 0.033 & $0.157^{* * *}$ & $0.109^{* * *}$ & $0.079^{*}$ & $0.074^{*}$ & -0.022 & -0.040 \\
\hline & $(0.049)$ & $(0.044)$ & $(0.041)$ & $(0.045)$ & $(0.045)$ & $(0.062)$ & $(0.118)$ \\
\hline \multirow[t]{2}{*}{ Low middle income } & 0.049 & $0.121^{* * *}$ & $0.104^{* * *}$ & $0.107^{* * *}$ & $0.083^{* *}$ & 0.028 & -0.025 \\
\hline & $(0.048)$ & $(0.041)$ & $(0.037)$ & $(0.040)$ & $(0.042)$ & $(0.060)$ & $(0.113)$ \\
\hline \multicolumn{8}{|c|}{ Age 18-29 (reference group) } \\
\hline \multirow[t]{2}{*}{ Age 30-39 } & $-0.331^{* * *}$ & 0.0273 & $-0.122^{* * *}$ & $-0.185^{* * *}$ & $-0.287^{* * *}$ & $-0.359 * * *$ & $-0.664^{* * *}$ \\
\hline & $(0.052)$ & $(0.046)$ & $(0.040)$ & $(0.044)$ & $(0.044)$ & $(0.063)$ & $(0.120)$ \\
\hline \multirow[t]{2}{*}{ Age 40-49 } & $-0.412^{* * *}$ & 0.054 & $-0.105^{* *}$ & $-0.186^{* * *}$ & $-0.382^{* * *}$ & $-0.509^{* * *}$ & $-0.849^{* * *}$ \\
\hline & $(0.054)$ & $(0.047)$ & $(0.042)$ & $(0.045)$ & $(0.046)$ & $(0.065)$ & $(0.127)$ \\
\hline \multirow[t]{2}{*}{ Age $50-59$} & $-0.307^{* * *}$ & $0.150^{* * *}$ & 0.007 & -0.050 & $-0.263^{* * *}$ & $-0.437^{* * *}$ & $-0.766^{* * *}$ \\
\hline & $(0.057)$ & $(0.050)$ & $(0.046)$ & $(0.049)$ & $(0.048)$ & $(0.068)$ & $(0.135)$ \\
\hline \multirow[t]{2}{*}{ Age 60-69 } & -0.083 & $0.382^{* * *}$ & $0.292^{* * *}$ & $0.219^{* * *}$ & 0.014 & $-0.200^{* * *}$ & $-0.679^{* * *}$ \\
\hline & $(0.062)$ & $(0.055)$ & $(0.047)$ & $(0.050)$ & $(0.051)$ & $(0.073)$ & $(0.146)$ \\
\hline \multicolumn{8}{|l|}{ Male (reference group) } \\
\hline \multirow[t]{2}{*}{ Female } & $0.763^{* * *}$ & $0.489^{* * *}$ & $0.574^{* * *}$ & $0.704^{* * *}$ & $0.828^{* * *}$ & $0.952^{* * *}$ & $0.986^{* * *}$ \\
\hline & $(0.031)$ & $(0.028)$ & $(0.026)$ & $(0.028)$ & $(0.028)$ & $(0.039)$ & $(0.075)$ \\
\hline \multicolumn{8}{|l|}{ Single (reference group) } \\
\hline \multirow[t]{2}{*}{ Married } & $0.156^{* * *}$ & $0.235^{* * *}$ & $0.271^{* * *}$ & $0.228^{* * *}$ & $0.235^{* * *}$ & $0.126^{* *}$ & -0.091 \\
\hline & $(0.043)$ & $(0.039)$ & $(0.034)$ & $(0.037)$ & $(0.037)$ & $(0.052)$ & $(0.099)$ \\
\hline Separated & 0.003 & -0.068 & 0.016 & -0.045 & 0.022 & 0.011 & -0.090 \\
\hline & $(0.068)$ & $(0.050)$ & $(0.046)$ & $(0.050)$ & $(0.052)$ & $(0.076)$ & $(0.141)$ \\
\hline Household with no kids ( & & & & & & & \\
\hline Household with kids & $0.137^{* * *}$ & $0.086^{* * *}$ & $0.120^{* * *}$ & $0.128^{* * *}$ & $0.104^{* * *}$ & $0.157^{* * *}$ & 0.083 \\
\hline & $(0.035)$ & $(0.031)$ & $(0.029)$ & $(0.031)$ & $(0.031)$ & $(0.044)$ & $(0.085)$ \\
\hline Weak social interaction ( & & & & & & & \\
\hline Strong social interaction & $0.379^{* * *}$ & $0.283^{* * *}$ & $0.309^{* * *}$ & $0.346^{* * *}$ & $0.414^{* * *}$ & $0.454^{* * *}$ & $0.374^{* * *}$ \\
\hline & $(0.032)$ & $(0.029)$ & $(0.027)$ & $(0.029)$ & $(0.029)$ & $(0.041)$ & $(0.078)$ \\
\hline Never smoker (reference & & & & & & & \\
\hline Current smoker & $-0.613^{* * *}$ & $-0.430^{* * *}$ & $-0.571^{* * *}$ & $-0.558^{* * *}$ & $-0.632^{* * *}$ & $-0.685^{* * *}$ & $-0.702^{* * *}$ \\
\hline & $(0.042)$ & $(0.036)$ & $(0.034)$ & $(0.036)$ & $(0.037)$ & $(0.053)$ & $(0.010)$ \\
\hline Former smoker & $-0.082^{* *}$ & -0.037 & $-0.103^{* * *}$ & $-0.080^{* *}$ & $-0.056^{*}$ & -0.063 & -0.102 \\
\hline & $(0.036)$ & $(0.033)$ & $(0.030)$ & $(0.033)$ & $(0.033)$ & $(0.046)$ & $(0.087)$ \\
\hline Canadian born (reference & & & & & & & \\
\hline Immigrant & -0.044 & 0.031 & 0.021 & 0.013 & 0.023 & -0.050 & -0.093 \\
\hline & $(0.042)$ & $(0.042)$ & $(0.037)$ & $(0.040)$ & $(0.040)$ & $(0.056)$ & $(0.105)$ \\
\hline Quebec (reference group) & & & & & & & \\
\hline Ontario & $-0.741^{* * *}$ & $-0.266^{* * *}$ & $-0.341^{* * *}$ & $-0.433^{* * *}$ & $-0.749 * * *$ & $-1.000^{* * *}$ & $-1.200^{* * *}$ \\
\hline & $(0.045)$ & $(0.039)$ & $(0.035)$ & $(0.038)$ & (0.039) & $(0.056)$ & $(0.107)$ \\
\hline British Columbia & $-0.640^{* * *}$ & $-0.113^{* *}$ & $-0.223^{* * *}$ & $-0.311^{* * *}$ & $-0.585^{* * *}$ & $-0.933^{* * *}$ & $-1.120^{* * *}$ \\
\hline & $(0.052)$ & $(0.051)$ & $(0.044)$ & $(0.047)$ & $(0.047)$ & $(0.067)$ & $(0.126)$ \\
\hline
\end{tabular}


Table 2 Fruit and vegetable regression results: OLS and quantile estimates (Continued)

\begin{tabular}{lccccccc}
\hline Atlantic & $-1.109^{* * *}$ & $-0.467^{* * *}$ & $-0.699^{* * *}$ & $-0.797^{* * *}$ & $-1.057^{* * *}$ & $-1.413^{* * *}$ & $-1.512^{* * *}$ \\
Western & $(0.048)$ & $(0.046)$ & $(0.041)$ & $(0.043)$ & $(0.044)$ & $(0.062)$ & $(0.117)$ \\
& $-0.712^{* * *}$ & $-0.314^{* * *}$ & $-0.424^{* * *}$ & $-0.525^{* * *}$ & $-0.729^{* * *}$ & $-0.937^{* * *}$ & $-1.059^{* * *}$ \\
Constant & $(0.049)$ & $(0.043)$ & $(0.038)$ & $(0.042)$ & $(0.043)$ & $(0.061)$ & $(0.118)$ \\
& $4.702^{* * *}$ & $0.823^{* * *}$ & $1.822^{* * *}$ & $2.490^{* * *}$ & $4.084^{* * *}$ & $6.126^{* * *}$ & $8.717^{* * *}$ \\
& $(0.070)$ & $(0.061)$ & $(0.060)$ & $(0.063)$ & $(0.062)$ & $(0.087)$ & $(0.168)$
\end{tabular}

Standard errors are in parentheses. ${ }^{* *} p<0.01,{ }^{* *} p<0.05,{ }^{*} p<0.1$. The estimates are population weighted using the CCHS sampling weights.

(see Figure 1) that females consume F\&V more often than males. The OLS estimates show that on average, the daily F\&V consumption frequency for females is 0.76 more than males. The quantile regression results show that this gender gap in $F \& V$ consumption frequency increases at higher quantiles on the conditional F\&V distribution. Results show that smoking is significantly associated with low F\&V consumption, where both current smokers and former smokers consume F\&V less often than never smokers. On average, current smokers consume F\&V less frequently compared to never smokers. This variation in F\&V consumption frequency by smoking status is greater at higher percentiles of the conditional F\&V distribution. We find that there is no statistically significant difference in F\&V consumption between immigrants and natives. Also, results show that household composition significantly affects the frequency of F\&V consumption. Married individuals and those with children consume F\&V more often compared to their reference groups. Individuals with strong social

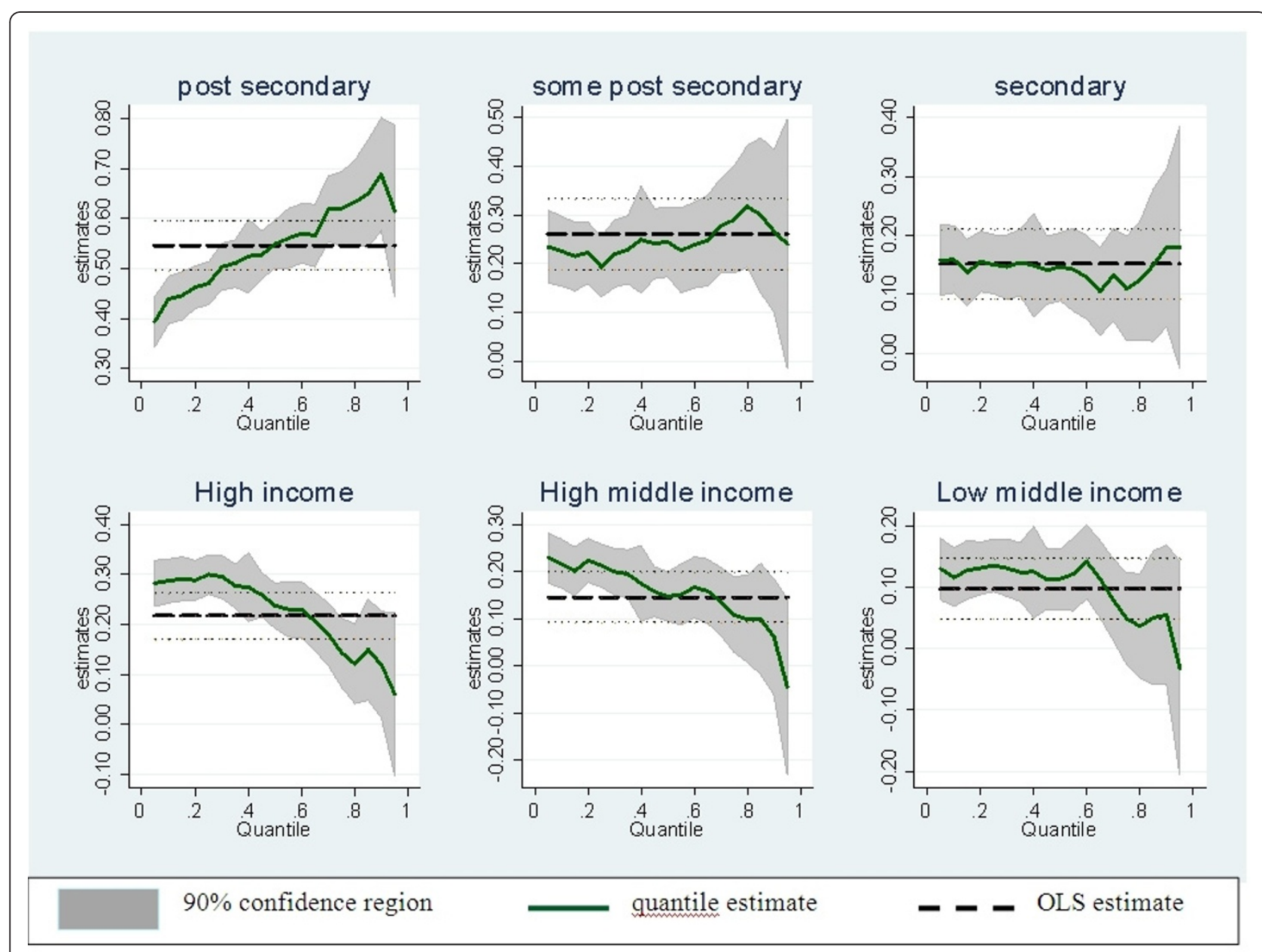

Figure 2 Quantile regression estimates across conditional quantiles of the F\&V distribution by socio-economic characteristics. 
interaction consume $\mathrm{F} \& \mathrm{~V}$ more frequently than those with weaker social interaction.

F\&V consumption frequency follows a U-shaped pattern across the age categories. Those aged 30-39, 40-49 and $50-59$ years consume $F \& V$ less frequently than those aged 18-29 years. The smallest F\&V consumption is among the middle aged adults (40-49).

The OLS results show no statistically significant difference in F\&V consumption frequency between seniors (60$69)$ and the young (18-29), while the quantile estimates indicate a statistically significant difference. Seniors consume F\&V more often than the young below the median. This pattern is reversed at the upper percentiles of the F\&V consumption distribution. In line with the unconditional analysis, results from both the OLS and quantile regressions reveal the existence of a SES gradient in F\&V consumption, where the low income-education groups consume F\&V less often than the high income-education groups. The extent of this SES gradient varies across the conditional quantiles of the F\&V consumption distribution. While individual educational attainment is positively and significantly associated with F\&V consumption frequency across different parts of the F\&V distribution, income level matters only at the lower half of the distribution. Figure 2 shows that the OLS model understates (overstates) the effect of income level on F\&V consumption at the lower (higher) quantiles of the conditional F\&V distribution. We find significant provincial differences in F\&V consumption, where the Atlantic, Western, British Columbia and Ontario provinces consume F\&V less often compared to the reference province (Quebec). The provincial effects are amplified at higher quantiles of the F\&V consumption distribution.

\section{Discussion and Conclusion}

In spite of the numerous health benefits from adequate consumption of $F \& V$, the dietary behavior of many individuals with respect to $F \& V$ consumption is below the daily recommended level. A large and growing literature has examined the determinants of F\&V consumption. Nonetheless, most previous studies are based on standard multiple linear or binary choice regressions. The findings from these estimation methods may lead to wrong policy intervention measures if individuals' $F \& V$ consumption responds differently to changes in the covariates at different regions of the $F \& V$ consumption distribution. Accordingly, we use a quantile regression to examine the disparities in F\&V consumption frequency by socio-demographic and lifestyle characteristics along different parts of the F\&V consumption distribution.

Both the conditional and unconditional analyses show significant disparities in F\&V consumption frequency among people with different socio-demographic and lifestyle features. We find that F\&V consumption is relatively lower among males, middle aged, singles, smokers, individuals with weak social interaction and households with no children. The results also reveal the existence of a SES gradient in F\&V consumption where, low income-education groups consume F\&V less often than the high incomeeducation group. Estimates from the quantile regression show that socio-demographic and lifestyle factors exert different effects on F\&V consumption frequency across the conditional quantiles of the F\&V distribution. There is no statistically significant difference in F\&V consumption between immigrants and natives. There are significant differences in $F \& V$ consumption between provinces, where the Atlantic, Western, British Columbia and Ontario provinces consume F\&V less frequently compared to Quebec. This result could be due to cultural influence, since Quebec is a predominantly a French-speaking province. Quebec also has a long history of farming most notably in fruit, vegetable and dairy products.

Several explanations have been used in the literature to justify the disparities in F\&V consumption by socio-demographic characteristics [e.g. [16-22]]. For example, it has been suggested that educational attainment affects nutritional knowledge and awareness about the risks associated with inadequate consumption of $F \& V$. One potential explanation for the disparities in $F \& V$ consumption by income level is due to the high price of F\&V. The difference in $\mathrm{F} \& \mathrm{~V}$ consumption by marital status may be due to family or household size, where individuals tend to consume more F\&V when eating meals with others [17].

The findings of this paper are consistent with several previous studies which find that men consume less F\&V than women [18,20-22], smokers consume less than nonsmokers [21,22], singles consume less than married people $[16,18]$ and that there is no significant difference by ethnicity $[16,25]$. The existence of a socioeconomic gradient in F\&V consumption is in line with the findings of several studies which find a positive association between income, level of education and F\&V consumption [16-19]

The current study has some limitations. First, the cross-sectional design of the data set limits ability to infer causality and does not allow us to control for unobserved factors that may affect the consumption of $F \& V$, such as preferences. This calls for further research using longitudinal data. Second, due to data set limitations, F\&V consumption data are based on a survey question that measures the number of times daily, respondents reported that they consumed F\&V. This F\&V consumption frequency may not reflect the actual quantity consumed [10].

Understanding the socio-demographic and lifestyle characteristics of individuals with low F\&V consumption frequency helps to identify the targeted groups for nutrition promotion policies aimed at encouraging F\&V consumption. Intervention measures need to take into 
account the potential heterogeneous effect of F\&V consumption determinants along the different quantiles of the F\&V distribution. There is no one-size-fits-all strategy to promote healthy eating behavior; a multifaceted approach would be required to address low consumption of F\&V successfully. For example, increasing people's awareness about the benefits of F\&V consumption, through the media and other community-organized nutrition programs, as well as subsidizing the cost of F\&V may be helpful in encouraging the consumption of $F \& V$, especially among people in low socioeconomic strata.

\section{Acknowledgements}

We thank two reviewers of this journal, Tatyana Koreshkova, Gordon Fisher, lan Irvine and Nikolay Gospodinov.

\section{Authors' contributions}

Both Authors contributed equally to the conceptualization, design and composition of the paper.

All authors read and approved the final manuscript.

\section{Competing interests}

The authors declare that they have no competing interests.

Received: 29 July 2011 Accepted: 25 October 2011

Published: 25 October 2011

\section{References}

1. Bazzano LA: The high cost of not consuming fruits and vegetables. J Am Diet Assoc 2006, 106(9):1364-1368.

2. Lock K, Pomerleau J, Causer L, Altmann DR, McKee M: The global burden of disease attributable to low consumption of fruit and vegetables: Implications for the global strategy on diet. Bull World Health Organ 2005, 83(2):100-108.

3. WHO: Diet, nutrition, and the prevention of chronic diseases., Report of a joint WHO/FAO expert consultation,2003 Technical Report Series 916.

4. Sargeant LA, Khaw KT, Khaw KT, Bingham SA, Bingham S, Day NE, Luben RN, Oakes S, Welch AA, Wareham NJ: Fruit and vegetable intake and population glycosylated haemoglobin levels: the EPIC-Norfolk Study. Eur J Clin Nutr 2001, 55(5):342-348.

5. Rolls BJ, Ello-Martin JA, Tohill BC: What Can Intervention Studies Tell Us about the Relationship between Fruit and Vegetable Consumption and Weight Management? Nutr Rev 2004, 62(1):1-17.

6. Tohill BC, Seymour J, Serdula M, Kettel-Khan L, Rolls BJ: What epidemiologic studies tell us about the relationship between fruit and vegetable consumption and body weight. Nutr Rev 2004, 62(10):365-374

7. He FJ, Nowson CA, MacGregor GA: Fruit and vegetable consumption and stroke: Meta-analysis of cohort studies. Lancet 2006, 367(9507):320-326.

8. Alonso A, de la Fuente C, Martín-Arnau AM, de Irala J, Martínez JA, Martínez-González MA: Fruit and vegetable consumption is inversely associated with blood pressure in a Mediterranean population with a high vegetable-fat intake: The Seguimiento Universidad de Navarra (SUN) Study. Brit J Nutr 2004, 92(2):311-319.

9. WHO: The World Health Report 2002- Reducing Risks, Promoting Healthy Life.[http://www.who.int/whr/2002/en/].

10. Statistics Canada: Fruit and vegetable consumption.[http://www.statcan.gc. ca/pub/82-625-x/2011001/article/11461-eng.htm].

11. Center for Disease Control and Prevention: State-Specific Trends in Fruit and Vegetable Consumption among Adults- United States, 2000-2009. MMWR 2010, 59(35):1125-1130

12. Anderson A, Hunt K: Who are the 'healthy eaters'? Eating patterns and health promotion in the west of Scotland. Health Educ J 1992, 51(1):3-10.

13. Reime B, Novak P, Born J, Hagel E, Wanek V: Eating habits, health status, and concern about health: a study among 1641 employees in the German metal industry. Prev Med 2000, 30(4):295-301.
14. Kristal AR, Patterson RE, Glanz K, Heimendinger J, Hebert JR, Feng Z, Probart C: Psychosocial correlates of healthful diets: baseline results from the working well study. Prev Med 1995, 24(3):221-228.

15. Smith AM, Baghurst KI: Public health implications of dietary differences between social status and occupational groups. J Epidemiol Commun $\mathrm{H}$ 1992, 46(4):409-416.

16. Riediger ND, Moghadasian MH: Patterns of Fruit and Vegetable Consumption and the Influence of Sex, Age and Socio-Demographic Factors among Canadian Elderly. J Am Coll Nutr 2008, 27(2):306-313.

17. Rasmussen M, Krolner R, Klepp KI, Lytle L, Brug J, Bere E, Due P: Determinants of fruit and vegetable consumption among children and adolescents: a review of the literature. Part I: quantitative studies. Int $J$ Behav Nutr Phys Act 2006, 3:22.

18. Nepal VP, Mgbere O, Banerjee D, Arafat RR: Disparities in Fruits and Vegetables Consumption in Houston, Texas: Implications for Health Promotion. Journal of Primary Care \& Community Health 2011, 2(3):142-147.

19. Ricciuto $L$, Tarasuk $V$, Yatchew A: Socio-demographic influences on food purchasing among Canadian households. Eur J Clin Nutr 2006, 60:778-790.

20. Baker $A H$, Wardle J: Sex differences in fruit and vegetable intake in older adults. Appetite 2003, 40(3):269-275.

21. Perez CE: Fruit and vegetable consumption. Health Rep 2002, 13:23-31.

22. Thompson RL, Margets BM, Speller VM, McVey D: The health education authority's health and lifestyle survey 1993: who are the low fruit and vegetable consumers? J Epidemiol Community H 1999, 53:294-299.

23. Auld MC, Powell LM: Economics of Food Energy Density and Adolescent Body Weight. Economica 2009, 76:719-740.

24. Statistics Canada: Canadian Community Health Survey Derived Variable Specifications.[http://www.statcan.gc.ca/imdb-bmdi/document/ 3226_D2_T9_V6-eng.pdf].

25. Devine CM, Wolfe WS, Frongillo EA, Bisogni CA: Life-course events and experiences: association with fruit and vegetable consumption in 3 ethnic groups. J Am Diet Assoc 1999, 99(3):309-314.

\section{doi:10.1186/1475-2891-10-118}

Cite this article as: Azagba and Sharaf: Disparities in the frequency of fruit and vegetable consumption by socio-demographic and lifestyle characteristics in Canada. Nutrition Journal 2011 10:118.

\section{Submit your next manuscript to BioMed Central and take full advantage of:}

- Convenient online submission

- Thorough peer review

- No space constraints or color figure charges

- Immediate publication on acceptance

- Inclusion in PubMed, CAS, Scopus and Google Scholar

- Research which is freely available for redistribution
Ciomed Central 